\title{
CONSTRAINING AND ENHANCING FACTORS OF BUSINESS ENTERPRISE IN OCCIDENTAL MINDORO, PHILIPPINES
}

\author{
Ryan Mark A. Ambong \\ Science Research Specialist I, Research, Development and Extension Unit, \\ Occidental Mindoro State College, Philippines \\ Liberty R. Mendaña, DPA \\ Assistant Professor III, College of Business, \\ Administration and Management, Occidental Mindoro State College, Philippines
}

\begin{abstract}
This paper aims to determine the constraining and enhancing factors of key business enterprise in Occidental Mindoro, Philippines. The Michael Porter's Diamond Model of Competitive Advantage was used as the analytical framework. Data obtained from the survey were analysed using Descriptive Statistics. The research revealed that businesses are negatively constrained by three most critical factors such as insufficient and unreliable electric supply, unfavorable tax system and the cost of transport which is very important since Occidental Mindoro is an island province. The enhancing factors, on the other hand, are the incentives in the compensation of management, favorable market size and the nature of competitive advantage which are unique among industries. However, this study also revealed that the environment for the business enterprise is not enabling because majority of the competitive determinants showed competitive disadvantage.
\end{abstract}

Keywords: Small and Medium Enterprises, Competitiveness, Competitive Advantage, Michael Porter's Diamond Model, Business Environment.

Cite this Article: Ryan Mark A. Ambong and Liberty R. Mendaña, DPA, Constraining and Enhancing Factors of Business Enterprise In Occidental Mindoro, Philippines. International Journal of Management, 10 (2), 2019, pp. 9-16. http://iaeme.com/Home/issue/IJM?Volume $=10 \&$ Issue $=2$

\section{INTRODUCTION}

Small and medium enterprises (SMEs) dominate the Philippine business firms accounting for $99.1 \%$ while the remaining $0.99 \%$ comprises the large enterprises. Statistics from the year 2008 accounts that there were about around 761,000 registered enterprises of which $91.6 \%$ were accounted for by micro enterprises. On the other hand, the other $7.7 \%$ and $0.4 \%$ are the shares accounted for the small and medium enterprises, respectively. According to Aldaba (2012), he 

Philippines

major constraints affecting the performance and competitiveness of the SMEs is the poor access of the entrepreneurs to financing which means they are not able to start, innovate, grow, and develop their enterprise through requesting of funds from banks and other financing institution. It is however prominent that the SMEs in the Philippines as compared to large enterprises are more efficient when it comes to resource utilization. Moreover, they are being characterized as dynamic and productive, and vital for country's economic growth, employment creation and innovation.

Considering the investment environment of the Philippines, SMEs are able to take advantage of the existence of open market economy, reliable infrastructure support, available special economic zones and strategic location, hospitable lifestyle, competitive investment incentives as well as quality human resources (Bitonio, n.d).

In terms of the nature of business, the Philippine SMEs are categorized according to types: Manufacturing, Service Business (business service, personal service, repair service, entertainment and recreation, hospitality, and education services), Trading Business, Rentals, and Agri and Aqua Business.

Data from the Department of Trade and Industry (DTI) revealed that sector of wholesale and retail trade obtained almost $50 \%$ of total share while $14 \%$ and $12 \%$ were for the manufacturing and hotel and restaurant sectors, respectively. Moreover, these enterprises are good generators of employment. In fact, 5.54 million of employment was generated in 2008 of which $31.2 \%$ was contributed by SMEs while micro enterprises shared almost the same of $30 \%$. The employment generated from wholesale and retail trade was roughly $35 \%$ of the total employment generated by SMEs. On the other hand, manufacturing shared $19 \%$ of employment.

In the manufacturing industry alone, 112, 377 are registered enterprise for 2008. In this case, $9.5 \%$ of employment came from SMEs contributing $28 \%$ of employment from a total generated employment of 1.4 million.

The province of Occidental Mindoro is the leading producer of rice in the Southern Tagalog Region and is a major source of agricultural commodities for the nearby provinces. It has a vast land with good potential for Agriculture and has a bright prospect for future growth and development. Through sustained productivity and favorable market access for its major products, the province can open wide opportunities for the potential entrants in business and budding entrepreneurs. Among the major factors that contribute to the success and failure of the business in Occidental Mindoro are the road infrastructures that impact the value chain of commodities and power supply which affects business transactions and rendering of public services. Other important bottlenecks are the market access and the current market's absorptive capacity. Given that the province is an island province, some businesses identified problems in the distribution chain as well as in the outsourcing of quality raw materials. Furthermore, the SMEs of Occidental Mindoro are also benefited with opportunities which they can take advantage to survive in the industry and to enhance their competitiveness. This study was conducted to determine the constraining and enhancing factors of key business enterprise in Occidental Mindoro, Philippines. Specifically, the study was done to determine the competitiveness of the business enterprise and its influencing factors.

\section{METHODOLOGY}

\subsection{Design and Theoretical Foundation of the Research}

According to Porter (1998), as stated by Dlamini, Kirsten, \& Masuku (2014), the analysis of the country's competitiveness requires the examination of the factors affecting the competitiveness of individual firms and industries. Furthermore, this study was anchored to 
Michael Porter's theory of nation-state competitive advantage declaring that a country may provide a competitive advantage for its firms. Using Porter's theory, this study adopted quantitative method of research in determining the factors that influence the competitiveness of SMEs in Occidental Mindoro, Philippines. This study utilized the Porter's Diamond model as its theoretical framework.

\subsection{Sampling and Collection of Data}

Samples were taken purposively from the list of registered businesses of the Department of Trade and Industry-Occidental Mindoro as of the year 2016. Eighty sets of self-administered questionnaires were utilized to obtain the opinions of selected enterprise/business managers about the factors that influence the competitiveness of their businesses. The questionnaire contains the Michael Porter's determinants of competitive advantage which are factor demand, related and supporting industries, firm's strategy and rivalry, government and chance conditions. The study was conducted from February to June, 2016.

\subsection{Data Analysis}

Constraining factors were rated with a mean of less than three, moderate factors with mean of three while enhancing factors with a mean above three (five being the maximum value). The competiveness of the businesses was determined by computing the overall mean rate of each factors combined under every determinant of competitive advantage (Dlamini, Kirsten, and Masuku, 2014).

\section{RESULTS AND DISCUSSION}

\subsection{Characteristics of the Small and Medium Enterprises (SMEs)}

This study conducted in the province of Occidental Mindoro was participated by various business establishments with the operational focus in the municipality of San Jose which is considered as the center for trade and commerce of the province. There were 80 selfadministered set of questionnaires distributed to key businesses registered under the local Department of Trade and Industry (DTI) and it has an 83.75 response rate were in only 67 businesses decided to participate on the survey.

The summary of the business participated on the survey is depicted on Table 1. With the figures appeared on the table, it is important to consider the fact that there are other businesses engaged in more than one kind of business activity.

Aside from value addition and retailing/distribution, $40.29 \%$ is engaged in product marketing and sales, while $31.34 \%$ are into agribusiness venture. According to the classification of the businesses by the DTI, firms or SMEs categorized under the sector of agribusiness are those that are engaged in in food production, farming and contract farming, seed supply, agrochemicals, farm machinery, wholesale and distribution, processing, marketing and retail sales. The $17.91 \%$ of the SMEs are engaged in the product handling/warehousing while the remaining sector comprising $10.45 \%$ are engaged in providing technical service such as repair and maintenance shops.

Table 1 Operational business focus of the SMEs.

\begin{tabular}{|l|c|c|}
\hline Type of Operation & $\begin{array}{c}\text { Frequency } \\
(\mathbf{N}=\mathbf{6 7})\end{array}$ & Percentage \\
\hline 1. Retailing/Distribution & 67 & 100.00 \\
\hline 2. Product Marketing and Sales & 27 & 40.29 \\
\hline 3. Agribusiness & 21 & 31.34 \\
\hline
\end{tabular}


Constraining and Enhancing Factors of Business Enterprise In Occidental Mindoro, Philippines

\begin{tabular}{|l|c|c|}
\hline 4. Technical Service Provider & 7 & 10.45 \\
\hline 5. Value Addition/Processing/Manufacturing & 67 & 100.00 \\
\hline 6. Product Handling/Warehousing & 12 & 17.91 \\
\hline
\end{tabular}

\subsection{Factor Conditions Affecting the Competitiveness of the SMEs}

Presented on the Table 2 are the factors that constrain the SMEs in Occidental Mindoro. These are the factor conditions that have an effect to their competitiveness as a business and as a member of an industry. Based on the result of the survey, the top three most important factor conditions which negatively affects the competitiveness of the SMEs are the sufficiency and reliability of electric supply (mean $=2.05$ ) which is very evident and has been experienced by businesses for the past years followed by tax system $($ mean $=2.10)$ and the cost of transport $($ mean $=2.26)$ which is very critical due to the geographic location of Occidental Mindoro being an island province. These factors were ranked according to the computed value of the mean responses where in the mean which have a value less than three but greater than or equal to one is considered as a constraining factor. Moreover, the survey revealed that there were 18 identified major factors constraining the SMEs wherein they are ordered according to their impacts on the businesses included on the survey.

Table 2 Constraining factors for the Small and Medium Enterprises.

\begin{tabular}{|l|c|}
\hline Factor Conditions & Mean \\
\hline 1. Sufficiency and reliability of electric supply & 2.05 \\
\hline 2. Tax system & 2.10 \\
\hline 3. Cost of transport & 2.26 \\
\hline 4. Cost of quality technology & 2.30 \\
\hline 5. Availability of water for industrial purposes and production & 2.31 \\
\hline 6. Limited scientific research institutions & 2.37 \\
\hline 7. Limited access to quality technology & 2.40 \\
\hline 8. Trust in politicians & 2.45 \\
\hline 9. Trade policies & 2.47 \\
\hline 10. Cost of unskilled and skilled labor & 2.68 \\
\hline 11. Transportation & 2.75 \\
\hline 12. Sustainability of local supplies & 2.80 \\
\hline 13. Cost of using infrastructures & 2.89 \\
\hline 14. Administration regulation & 2.89 \\
\hline 15. Changing consumer trends and preferences & 2.89 \\
\hline 16. Cost of supplies/inputs & 2.95 \\
\hline 17. Quality of local primary inputs & 2.95 \\
\hline 18. Speed of growth of market & 2.95 \\
\hline
\end{tabular}

In terms of the enhancing factors for the SMEs, the incentives in the compensation of management are considered the most important according to the business managers with a mean of 3.55. The local market size which is relatively encouraging for gaining market shares among competing firms is considered as the second-best enhancing factor (mean $=3.40)$ followed by the nature of competitive advantage (mean $=3.35$ ) which are unique in every types of businesses in the province. The competitive advantage is attained by the business through effective leadership and product differentiation. Other factors that provide competitive 
advantage are the technology, cost of inputs, economies of scale, product differentiation and quality, advertising and promotion and external factors like government policies (Harrison and Kennedy, 1997). The identified enhancing factors for the SMEs are summarized on Table 3 below.

Table 3 Enhancing factors for Small and Medium Enterprises.

\begin{tabular}{|l|c|}
\hline Factor Condition & Mean \\
\hline 1. Incentives in the compensation of management & 3.55 \\
\hline 2. Local market size & 3.40 \\
\hline 3. Nature of competitive advantage & 3.35 \\
\hline 4. Influence of business relation and networking & 3.30 \\
\hline 5. Effectiveness of personnel in public sector & 3.20 \\
\hline 6. Competency of personnel in public sector & 3.15 \\
\hline 7. Credit facilities & 3.05 \\
\hline
\end{tabular}

Aside from the given factor conditions that enhance and constrain the SMEs, there are also identified factors having moderate effects or which are not necessarily considered as a problem among the businesses participated in the survey. There are five factors with a mean of 3.00 considered as neither a constraint nor an enhancement. These are the unavailability of professional labor, cost of financing, production of affordable high-quality products, approach or investment to human resource and the production process. These factor conditions are enumerated on Table 4.

Table 4 Factors with moderate impacts to Small and Medium Enterprises.

\begin{tabular}{|l|c|}
\hline Factor Condition & Mean \\
\hline 1. Unavailability of professional labor & 3.00 \\
\hline 2. Cost of financing & 3.00 \\
\hline 3. Production of affordable high-quality products & 3.00 \\
\hline 4. Approach (Investment) to human resource & 3.00 \\
\hline 5. Production process & 3.00 \\
\hline
\end{tabular}

In Table 5, the factor conditions as determinant of the SMEs competitive advantage was highlighted. In totality, the factor conditions have an overall mean of 2.41 which explains that SMEs in Occidental Mindoro is experiencing a competitive disadvantage.

\subsection{General assessment of business enterprises' competitiveness}

\subsubsection{Demand Conditions}

In assessing the demand condition of an industry, it is important to look at the nature of the local demand for products and services. Demand conditions talk about the customers, the size and growth of the market as well as the customers' concern for ethics. Based on the determined factors of condition above, demand conditions are mostly constraining factors. Among these constraining factors are the changing consumer trends and preference $($ mean $=2.89)$ and the speed of growth of market (mean $=2.95)$. However, the size of the local market $($ mean $=3.40)$ turns out to be an enhancing factor since the local industry where the businesses belong is just right for enhancing competitiveness. Market size affects productivity and larger markets are more favorable in order to take advantage production efficiency or the economies of scale (Dlamini, Kirsten, and Masuku, 2014). The general assessment of the demand condition has an overall mean of 3.08 which indicates a relatively moderate competitive advantage. Business efficiency as the basis for profitability or profit rate determines competitiveness. Considering the company is competing for market sources as a buyer, its ability to access inputs and its 
dynamic characteristics determines competitiveness (Findrik-Szilard, 2000; Szentes et al., 2005; Chikan, 2006).

\subsubsection{Related and Supporting Industries Condition}

This condition is composed of the presence of credit facilities, scientific institutions and academes, telecommunication and electricity. Accordingly, business' competitiveness depends on the availability and unavailability of supplier and related industries which are also globally competitive. In this study, majority of the conditions under this domain are constraining factors. Thus, the top three constraining factors are insufficient and unreliable electric supply (mean = $2.05)$, limited supply of water (mean=2.31), and the absence of scientific research institution $($ mean $=2.37)$. Aside from other services, marketability of the products depends on the extent of marketing activities such as market research, advertising and other marketing communication activities as well as communication networks (Szentes et al., 2005; Botos, 1982). Most of the business managers interviewed complained about the unstable electricity which most of the time delays their business transactions. This problem has been perennial in Occidental Mindoro which primarily affects the firms engaged in processing and marketing of perishable and commodity-based products. Considering other contributing factors, related and supporting industry condition has an overall mean of 2.72 interpreted as a competitive disadvantage.

\subsubsection{Firm Strategy, Structure, and Rivalry Condition}

This determinant of competitive advantage includes the investment for research and development by the firms, the cause of local market competition and the human resource approach and investment. According to Porter (1998), this condition comprises the manner by which a business is being established, organized, and managed. The overall assessment rating $($ mean $=3.08)$ just like the demand conditions explain that this factor provides a fairly moderate competitive advantage to the SMEs. It also shows that business relation and networking (mean= 3.30) enhances competitive advantage while the investment or approach to human resource contributes moderate advantage to SMEs $($ mean $=3.00)$.

\subsubsection{Government Support Conditions}

Government policy can influence the business either positively or negatively. Likewise, tax and trade system and other administrative regulations impact the competitiveness of a business. Based on the survey result, government is a constraining factor in the competitiveness of the SMEs in Occidental Mindoro. Tax system (mean $=2.10)$, trust in politicians (mean $=2.45)$, and trade polices (mean $=2.47$ ) are the top three factors that negatively influence the competitiveness of SMEs according to the business managers interviewed. Considering other factors with regard to policy and other government regulations, the overall assessment for the government support condition is 2.89 interpreted as a source of competitive disadvantage to the SMEs.

\subsubsection{Chance Conditions}

Chance conditions are factors which are beyond the control of the businesses and the local government. Examples of these are the incidence of crime, the changes in the value of money and prices as well as the condition of politics. The overall mean of 2.45 based on the survey denotes that chance conditions also a source of competitive disadvantage for the SMEs. This competitive disadvantage was contributed by the loss of trust in politicians among the locals. Crime, although a potential influencer, has no significant impact on the performance of the SMEs. In South Africa, a study conducted by Esterhuisin (2006), three constraining factors in 
the competitiveness of agribusiness sector were identified. These are cost of crime, trust in political systems and low level of competency of public sector personnel.

Table 5 General assessment of business enterprises' competitiveness

\begin{tabular}{|l|c|}
\hline Determinant & Overall Mean \\
\hline 1. Factor condition & 2.41 \\
\hline 2. Demand conditions & 3.08 \\
\hline 3. Related and supporting industries condition & 2.72 \\
\hline 4. Firm strategy, structure, and rivalry condition & 3.08 \\
\hline 5. Government support conditions & 2.89 \\
\hline 6. Chance conditions & 2.45 \\
\hline \multicolumn{2}{|c|}{$<3=$ competitive disadvantage 3= moderate $>3=$ competitive advantage } \\
\hline
\end{tabular}

\section{CONCLUSIONS}

The general assessment of the competitiveness of the small and medium enterprises in Occidental Mindoro, Philippines indicates that businesses are negatively impacted and that the general environment for the business is not empowering the SMEs to become competitive. Among the determinants of competitive advantage using the Diamond Model of Michael Porter, the firm strategy, structure, and rivalry condition is contributing to the SMEs in order to become competitive. This interprets that there is organization and good leadership and they are being protected by the industry where they belong. Among the six determinants of competitive advantage, the factor conditions or the factors of production of the businesses is the most critical threat that negatively influence competitiveness.

\section{REFERENCES}

[1] Aldaba, R.M., Small and Medium Enterprises' (SMEs) Access to Finance: Philippines. Discussion Paper Series No. 2012-05. Philippine Institute of Development Studies, 2012.

[2] Bitonio, J. B. (n.d). Philippines Micro Small Medium Enterprises (MSMEs). Retrieved form Url https://www.slideshare.net/jobitonio/philippines-micro-small-medium-enterprises-msmes

[3] Sri Handayani, Udin, Suharnomo, Ahyar Yuniawan, Sugeng Wahyudi, Tri Wikaningrum, A Systematic Literature Review of Managing Workplace Diversity for Sustaining Organizational Competitive Advantage, International Journal of Mechanical Engineering and Technology 8(12), 2017, pp. 398-406.

[4] Botos, J, International Competitiveness and the Price Revolution. Jogi Konyvkiado, Budapest, 1982.

[5] Chikan, et al, Corporate Competitiveness in a Globalizing Hungarian Economy. Akademiai Kaido, Budapest, 2002.

[6] Department of Trade and Industry SMED Council. SME Development Plan 2004-2010. Published by Bureau of Small and medium Enterprise Development (BSMED), Makati City, Philippines.

[7] Md Yousuf Chowtupalli and S. Abdul Rafi, Achieving Sustainable Competitive Advantage Through Resource Configuration and Organizational Identity: An Empirical Study, International Journal of Management (IJM), Volume 4, Issue 3, (May - June 2013), pp. 111-124

[8] Department of Trade and Industry SMED Council. SME Development Plan 2010-2016 (draft).

[9] Dlamini, B.P., Kirsten, J.F.; and Masuko, M.B, Factors Affecting the Competitiveness of the Agrbusiness Sector in Swaziland. Journal of Agricultural Studies. Vol 2, No. 1, 2014, pp 61 72.

[10] Esterhuizin, D, an Evolution of the Competitiveness of the South African Agribusiness Sector. University of Pretoria etd - Esterhuizen, D,2006 
Constraining and Enhancing Factors of Business Enterprise In Occidental Mindoro, Philippines

[11] Wahyu Setiyaningrum and Jasanta Peranginangin, Convergent Strategy towards Competitive and Sustainability Competitive Advantages in Online Media Competition. International Journal of Civil Engineering and Technology, 9(1), 2018, pp. 499-507

[12] Gal, A.N, Competitiveness of small and medium sized enterprise- a possible analytical framework. 2010, HEJ: ECO 100115-A

[13] Kennedy, P. L. R., Harrison, N. G., \& Piedra, M. A, Analyzing Agribusiness Competitiveness. The case of the United States Sugar Industry. JAI Press Inc,1998

[14] Kotler, P. and Keller, K.L, Marketing Management, New Jersey, 2006

[15] National Statistics Office and Small and Medium Enterprise Development Council Resolution No. 1, Series 2003.

[16] Ahyar Yuniawan, Vini Wiratno Putri and Udin, Developing an Alternative Model for the Relationship among Social Capital, Adaptive-Integrative Leadership, Competitive Advantage, and Organizational Effectiveness. International Journal of Civil Engineering and Technology, 8(11), 2017, pp. 52-60

[17] OECD, Globalization and Competitiveness: Relevant Indicators. Paris, 1994

[18] Porter, M. E, Akademiai Kiado, Budapest. (Porter, M.E. 1980): Competitive Strategy. Techniques for Analyzing Industries and Competitors. The Free Press, New York, 2006

[19] J B Tiwari, Developing Competitive Advantage Though Brand Building: An Analysis of Agro Chemical Companies in India, International Journal of Marketing and Human Resource Management (IJMHRM), Volume 6, Issue 1, January - April (2015), pp. 13-22

[20] Porter, M. E, The competitive Advantage of Nations. London, Mcmillan Press LTD, 1998

[21] Somoray, A. M. M. (n.d). Entrepreneurship and Business Planning. Lecture Compilation.

[22] Szentes, et al, Development Competitiveness Globalization I. Akademiai Kiado, Budapest, 2005 